\title{
Contributions of the Body Mass Index, Obstruction, Dyspnea, and Exercise Capacity or BODE index to Chronic Obstructive Pulmonary Disease
}

Bartolome R. Celli

Harvard Medical School, Boston, Massachusetts, USA

\section{ABSTRACT}

Chronic obstructive pulmonary disease is an important cause of disability and death around the world. The disease has been classically characterized by the presence of airflow limitation resulting from airway inflammation and remodeling as well as parenchymal destruction or emphysema. The severity and progression of chronic obstructive pulmonary disease has been classically defined by the degree of airflow limitation measured with the forced expiratory volume in one second during a forced vital capacity maneuver. However, observational and experimental studies have shown that chronic obstructive pulmonary disease is a respiratory disease associated with several systemic manifestations that actually impart a poor prognosis. Therefore it has become clear that there is a need to quantify and incorporate measurement of one or more of those dimensions in order to better reflect the actual compromise of patients. Based on findings from a large observational cohort, we determined that the body mass index (B), the severity of airflow limitation (O), degree of dyspnea (D) and the distance walked over six minutes (E) (i.e. BODE) were amongst the several clinical variables that related independently to mortality. The multidimensional BODE index developed by the integration of those variables into a single $0-10$ scale has been shown to predict not only all-cause and respiratory mortality, but also to respond to interventions such as lung transplant, lung volume reduction surgery, and pulmonary rehabilitation. This monograph summarizes the information that supports the concept that the BODE index can be used to define chronic 
obstructive pulmonary disease severity and staging of disease. Importantly, the information available shows that BODE can serve as a surrogate marker of disease progression and response to therapy. (BRN Rev. 2015;1:3-12)

Corresponding author: Bartolome R. Celli, bcelli@copdnet.org

Key words: BODE index. COPD. Severity. Staging.

\section{INTRODUCTION}

Chronic obstructive pulmonary disease (COPD) is a major cause of morbidity and mortality in adults and currently represents the fourth leading cause of death in the world ${ }^{1}$. It has become a major and growing health problem, with a mortality rate that continues to increase. It is the only leading cause of death showing increases in prevalence worldwide and it is expected that by the year 2020, COPD will become the third leading cause of death and the number one cause of disability in adults ${ }^{2}$.

Chronic obstructive pulmonary disease is primarily characterized by the presence of airflow limitation that responds poorly to bronchodilators. The limitation to airflow results from airway inflammation and remodeling and/or parenchymal destruction (emphysema), which frequently coexist ${ }^{3,4}$. However, there is a body of data that associate COPD to systemic manifestations that can effectively signal an increased risk for mortality ${ }^{5-7}$. Recognizing these manifestations provides a more comprehensive assessment of disease severity and can improve disease prognosis. This monograph reviews the following concepts and how they relate to COPD:

- Definition of disease severity and staging.
- Development of BODE as an index to define COPD severity and staging.

- Use of BODE to monitor COPD progression and response to therapy.

- Conclusions.

\section{DEFINITION OF DISEASE SEVERITY AND STAGING}

There is no agreement about the definition of disease severity or staging, but some information can be used to develop the appropriate framework. Two characteristics should define the specific severity of a disease and have to be present to provide a valid classification for a specific disease. First, the variables used to quantitate severity should reflect the likelihood of death, and second and importantly, they should reflect organ compromise or failure resulting from disease progression, independent of the treatment process. In this regard, the severity of COPD should not only define the outcome of the person as a whole (all-cause mortality), but also relate to the failure of the organ (in the case of COPD, respiratory mortality, hospitalizations from COPD, or disability from the disease). For example, age is certainly associated with a poor outcome (older people are 


\section{Multiple dimensions in COPD}

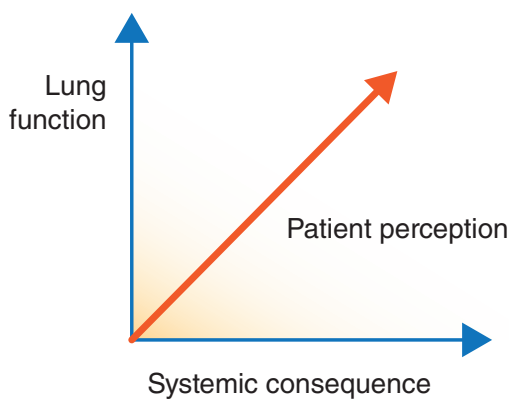

Figure 1. The different domains in which chronic obstructive pulmonary disease affects an individual can be measured with current clinical variables. Ideally, they would be integrated into a single final score.

COPD: chronic obstructive pulmonary disease.

more likely to die than younger ones), but may not relate to failure of the lung itself. In this regard, comorbidities will certainly impact on mortality and poor health status, but may not relate to the severity of the organ compromise. Thus, a system designed to classify COPD severity should fulfill the principles outlined above.

On the other hand, staging reflects a period or phase in the course of a disease, a concept that introduces the inclusion of time and progression. Thus the variable or variables used to stage a disease should be able to change over time. The "stage" of a disease is used not only to reflect severity, but also to plan therapy or resources investment. For COPD, severity and staging are usually associated and very difficult to separate. The inclusion of variables that cannot change over time should not be part of a disease staging system; such is the case of age or gender.

\section{THE BODE INDEX TO DEFINE CHRONIC OBSTRUCTIVE PULMONARY DISEASE SEVERITY AND STAGING}

Several clinical or laboratory outcomes have been identified as individual predictors of organ dysfunction disability and/or mortality in COPD (Fig. 1). These include the forced expiratory volume in one second $\left(\mathrm{FEV}_{1}\right)^{8-10}$, airways hyper-responsiveness ${ }^{8,11}$, severity of dyspnea $^{12}$, gas exchange disturbances ${ }^{13}$, lung hyperinflation ${ }^{14,15}$, pulmonary hypertension ${ }^{16}$, malnutrition ${ }^{17}$, impaired exercise capacity ${ }^{18-20}$, health-related quality of life ${ }^{20}$, and anemia ${ }^{21,22}$. As mentioned previously, age and the presence of other comorbidities also add to the global prognosis of patients with COPD, but are not by definition expressions of the disease process in the lung itself and therefore I shall not use them to define disease severi$\mathrm{ty}^{23,24}$. In this monograph, we will review these individual variables as predictors of mortality, hospitalizations for COPD, and disability. We will also discuss the power of BODE as an integrated, multidimensional tool to more broadly characterize COPD severity and assess response to therapeutic intervention as well.

\section{Predictors of outcome in chronic obstructive pulmonary disease and development and validation of BODE}

The initial step in the development of a multidimensional index should be to study the potential variables that could relate to the outcomes, as mentioned before. Table 1 shows a list of the variables that a review of the literature at the time the BODE cohort was 
TABLE 1. Properties of the potential variables to be included in the generation of the multidimensional evaluation of patients with chronic obstructive pulmonary disease

\begin{tabular}{|c|c|c|c|c|c|}
\hline Variable & All-cause mortality & Respiratory mortality & Hospitalizations & Disability & Ease of test \\
\hline FVC & Strong & Strong & Strong & Strong & Moderate \\
\hline $\mathrm{FEV}_{1}$ & Very strong & Very strong & Very strong & Very strong & Moderate \\
\hline $\mathrm{PaO}_{2}$ & Very strong & Very strong & Unknown & Strong & Moderate \\
\hline $\mathrm{PaCO}_{2}$ & Moderate & Moderate & Weak & Weak & Moderate \\
\hline 6MWD & Very strong & Very strong & Strong & Very strong & Difficult \\
\hline Dyspnea & Very strong & Strong & Strong & Very strong & Easy \\
\hline Albumin & Moderate & Moderate & Weak & Moderate & Easy \\
\hline Anemia & Weak & NA & NA & Moderate & Easy \\
\hline AHR & Moderate & NA & NA & Weak & Very difficult \\
\hline PAH & Moderate & Moderate & Moderate & Strong & Very difficult \\
\hline Age & Very strong & Weak & Moderate & Moderate & Easy \\
\hline Charlson index & Strong & Weak & Strong & Strong & Moderate \\
\hline
\end{tabular}

FVC: forced vital capacity; $\mathrm{FEV}_{1}$ : forced expiratory volume in one second; $\mathrm{PaO}_{2}$ : partial pressure of arterial oxygen; $\mathrm{PaCO}_{2}$ : partial pressure of arterial carbon dioxide; $\mathrm{AHR}$ : airway hypereactivity; PAH: pulmonary artery hypertension.

assembled suggested a relationship with poor outcomes. From these, we selected those with the strongest support from the literature ${ }^{25}$. These included variables related to lung function, such as forced vital capacity (FVC), $\mathrm{FEV}_{1}$, functional residual capacity (FRC), and inspiratory capacity (IC) and arterial blood gases $\left(\mathrm{PaO}_{2}\right.$ and $\left.\mathrm{PaCO}_{2}\right)$. Dyspnea was evaluated with the Modified Medical Research Council (MMRC) scale. As an expression of the impact of the disease on functional capacity, we selected the six-minute walk distance (6MWD), and for nutritional status the body mass index (BMI). We also evaluated albumin and hemoglobin as well as smoking intensity, with pack/ years as they had been associated with COPD. Finally, we also included age and the Charlson comorbidity score to evaluate whether the index to be developed was independent of these factors. The first 207 patients recruited were followed for one year and 25 of them died.
There were differences between survivors and non-survivors in all of the variables evaluated except in the pack years, FRC, and albumin. However, the significance of the difference varied for the different tests, being strongest for the $\mathrm{FEV}_{1}$ percentage of predicted, the MMRC dyspnea scale, the 6MWD, and BMI. Based on this, on the fact that these variables measured different domains and in addition were independently associated with all-cause and respiratory mortality, we decided to include them in the creation of the index (Fig. 2). Neither age nor comorbidities were included in this process because they are independent predictors of mortality, but not of respiratory mortality or COPD disability. In addition, the variables selected are relatively easy to measure and can respond to therapy or change over time.

The acronym BODE was derived from the initials of each of the components (BMI, 


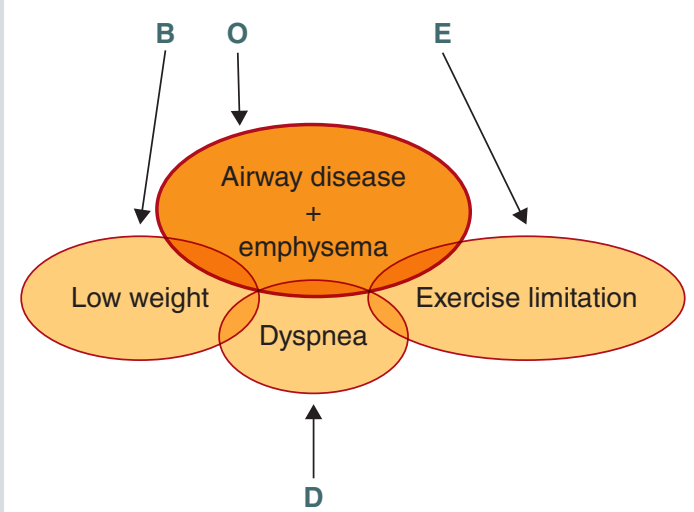

Figure 2. Domains included in the BODE chronic obstructive pulmonary disease severity index.

obstruction, dyspnea, and exercise performance). The weight for each variable was derived iteratively by relating their individual predictive value at different thresholds. The BMI was assigned one single value because the relationship between BMI and mortality is relatively flat until it falls below the value of $21 \mathrm{~kg} / \mathrm{m}^{2}$. The values of BODE ranged from 0 (lowest possible) to 10. Exploratory evaluation of different weights to each of the variables resulted in no improvement in the predictive value of the index in the original cohort ${ }^{25}$. However, a study of a larger cohort by Puhan, et al. ${ }^{26}$ observed a better predictive value when more weight was assigned to the 6MWD.

Once the index was developed, it was tested and followed prospectively every 3-6 months for two years or until death in a cohort of 625 patients with COPD in five centers located in three countries (USA, Spain, and Venezuela). The BODE index predicted all-cause mortality with a $30 \%$ increase in risk of death per each unit increase in BODE index. Not only was all-cause mortality predicted, but more importantly, the association of the BODE index was even stronger with mortality from respiratory causes (HR: 1.62; 95\% CI: 1.48-1.77; $\mathrm{p}<0.001$ ), supporting the premise needed to develop a COPD severity system.

\section{BODE as a chronic obstructive pulmonary disease prognostic and staging tool}

Following its initial publication, many reports have tested the prognostic value of BODE for several outcomes. The first was the study by Ong, et al. ${ }^{27}$ who recruited 127 patients with COPD and determined their BODE index. The patients were followed for up to two years and the number of hospital admissions and mortality were documented. The investigators found the median BODE score to be lower among survivors than among non-survivors (4 vs. 6 , respectively; $p=0.003$ ) and a significant effect of the BODE scores on mortality (HR: 1.30; 95\% CI: 1.08-1.56; p = 0.006). The investigators used Poisson regression analysis to evaluate the effect of BODE scores on hospitalizations and found BODE to also be a predictor of this outcome. Exacerbations and hospitalizations were also predicted by BODE in a study that included the expanded original cohort followed over five years. In a study of 275 patients followed for an average of eight years, Marin, et al. ${ }^{28}$ showed that the mean time to a first COPD emergency room visit was 6.7, 3.6, 2.0, and 0.8 years for each BODE quartiles (all $\mathrm{p}<0.05$ ). Using ROC curves, the BODE index was a better predictor of exacerbation than $\mathrm{FEV}_{1}$ alone $(\mathrm{p}<0.01$ ). These findings have been replicated in the studies from several groups that have explored the predictive value of other multidimensional indices 
and compared them with BODE. Puhan, et al. developed the ADO index that included age, dyspnea, and degree of airflow obstruction ${ }^{26}$. They updated the BODE index, increasing the predictive value of the $6 \mathrm{MWD}$ value by giving it a higher weight in the index. The ADO and modified BODE index were both predictive of all-cause mortality better than the original BODE index. However, no other outcome except all-cause mortality was evaluated. Soler-Cataluña, et al. developed the BODEx index in which the 6MWD was substituted by the exacerbations ${ }^{29}$. This index was a good predictor of mortality and performed as well as the original BODE index; however, only all-cause mortality was evaluated. Three other variations on the BODE have been developed: the m-BODE where the exercise was measured using oxygen uptake substituting the $6 \mathrm{MWD}^{30}$, the i-BODE where the incremental shuttle walk test substituted the $6 \mathrm{MWD}^{31}$, and the BODEm where the San Diego dyspnea score substituted the MMRC dyspnea ${ }^{32}$. All of these indices performed as well as the original BODE index, with all-cause mortality as the outcome. However, no other outcome, such as respiratory mortality or hospitalizations, was evaluated. Jones, et al. developed the DOSE index that included dyspnea, obstruction, smoking, and exacerbations ${ }^{33}$. The DOSE index predicted exacerbations, health status, and exacerbations, but was not tested for mortality. There have been other indices including the DOREMI-BOX or dyspnea, rate of exacerbations, exercise, $\mathrm{BMI}$, and oxygenation ${ }^{34}$. The HADO index integrated health status questionnaire, activity determined also by a questionnaire, dyspnea, and degree of obstruction $^{35}$. The CPI score ${ }^{36}$ that includes quality of life, obstruction, age, BMI, exacerbations, and cardiovascular disease is complex, but it predicted death, hospitalization, and exacerbations but no test for respiratory mortality was reported. Other indices have had more methodological problems and poor validation, and those include the COPD severity score, or COPDSS, based on self-reported diagnosis of $\mathrm{COPD}^{37}$; the PILE index comprising leg strength, interleukin-6, airflow obstruction, and speed over 400 meters $^{38}$; the SAFE index including St. George's questionnaire, airflow limitation, and exercise performance; and the TARDI index ${ }^{39}$ which has age, BMI, dyspnea, cardiovascular risk, hospitalizations and $\mathrm{FEV}_{1}$ amongst its components. A summary of these indices, their methodology, and predictive value are shown in table 2 .

More recently, there are indices that incorporate the number or type of comorbidities based on the observation that multi-morbidity is a frequent occurrence in patients with COPD. The CODEX index incorporated comorbidities (measured by Charlson), degree of airflow obstruction, dyspnea, and previous severe exacerbations in over 900 patients ${ }^{40}$. The index predicted all-cause mortality better than the BODEx or ADO indices after hospital discharge. A few studies have attempted to compare several of these indices across a larger spectrum of patients. The COPD collaborative cohorts to assess multicomponent indices (COCOMIC) group in Spain collected data from several cohorts consisting in total of over 3,000 patients followed for up to 10 years ${ }^{41}$. In this analysis with all-cause mortality as the outcome, the BODE and its modifications (m-BODE, BODEx) had similar properties once adjusted for age.

The Global Initiative for Obstructive Lung Disease also developed a grading system, but 
TABLE 2. Comparison of different multi-dimensional indices in patients with chronic obstructive pulmonary disease

\begin{tabular}{|c|c|c|c|c|c|c|}
\hline Index and reference & $\begin{array}{l}\text { Derivative } \\
\text { cohort (n) }\end{array}$ & $\begin{array}{l}\text { Validating } \\
\text { cohort (n) }\end{array}$ & $\begin{array}{c}\text { All-cause } \\
\text { mortality }\end{array}$ & $\begin{array}{c}\text { Respiratory } \\
\text { mortality }\end{array}$ & Exacerbations & $\begin{array}{l}\text { Disease } \\
\text { progression } \\
\text { or response } \\
\text { to intervention }\end{array}$ \\
\hline BODE & Yes & Yes & Yes & Yes & Yes & Yes \\
\hline BODEx & Yes & No & Yes & No & Yes & No \\
\hline $\mathrm{mBODE}$ & Yes & Yes & No & No & No & No \\
\hline iBODE shuttle walk & No & Yes & Yes & No & No & No \\
\hline ADO & Yes & Yes & Yes & No & No & No \\
\hline DOSE & Yes & Yes & No & No & Yes & Yes \\
\hline DOREMI-BOX & Yes & Yes & Yes & No & No & No \\
\hline CPI & Yes & Yes & Yes & No & Yes & No \\
\hline HADO & Yes & No & Yes & Yes & No & No \\
\hline ABCD GOLD & No & Yes & Yes & No & Yes & No \\
\hline CODEX* & Yes & Yes & Yes & No & Yes & No \\
\hline $\mathrm{BODE}^{*}+$ COTE & Yes & Yes & Yes & Yes & No & No \\
\hline
\end{tabular}

*These indices include co-morbidities.

BODE: body mass index, obstruction, dyspnea and exercise index; BODEx: the exercise with six-minute walk distance is substituted by exacerbations; mBODE: the exercise with six-minute walk distance is substituted by peak oxygen uptake; iBODE: the exercise with six-minute walk distance is substituted by the incremental shuttle walk distance; ADO: age, dyspnea, obstruction index; DOSE: dyspnea, obstruction, smoking status, exacerbations index; DOREMI-BOX: dyspnea, rate of exacerbations, exercise, body mass index, and oxygenation; CPO: COPD, prognostic index; HADO: health status, activity, dyspnea, obstruction index; ABCD GOLD: Global initiative of obstructive lung disease, ABCD grading; CODEX: comorbidity (Charlson index), obstruction, dyspnea, exacerbation; COTE: COPD comorbidity index.

did it without validation ${ }^{4}$. The system includes $\mathrm{FEV}_{1}$, dyspnea or health status, and exacerbations. Then, using absolute thresholds, the patients are placed in one of four grades: $A, B, C$ and $D$. In the only study where the $A B C D$ grading system was compared with the BODE, De Torres, et al. ${ }^{42}$ added the COTE comorbidity index to BODE, and in this study the $\mathrm{C}$ statistic for mortality offered the highest value reported of 0.81 (95\% CI: 0.77-0.86). This was significantly better than the ABCD or BODE alone. BODE on its own (C statistic 0.63 ) was better than the ABCD (C statistic 0.54), $(\mathrm{p}<0.001)$.

Taken together, all of these studies have confirmed that multidimensional indices are better than individual variables to predict mortality and in the case of BODE, exacerbations and hospitalizations as well as respiratory mortality.

However, all of the studies cited lack a crucial element; none has been tested to see if their implementation improves clinical outcomes. Some authors recommend stopping creating more indices, but rather to plan and complete studies designed to test whether incorporating the use of any index in the clinic improves care of patients with COPD. In a series of reviews aimed at helping guide the development of prognostic indices, Moons, et al. clearly state that it is best to calibrate already developed indices rather than to continue to develop new ones ${ }^{43}$. 


\section{BODE to monitor chronic obstructive pulmonary disease progression}

The concept that BODE reflects disease progression has been explored in several studies. Cote, et al. assessed the impact of exacerbations on BODE and its components ${ }^{44}$. In this study that lasted two years, 205 patients were recruited and evaluated with the BODE index at baseline while stable, then during the exacerbation event and every six months thereafter. A total of 130 patients experienced exacerbations and 75 patients remained exacerbation-free for the duration of the study. Exacerbators showed a worsening of BODE index of 1.38 points during the exacerbation, and although there was a partial improvement, the BODE index at 24 months remained 1.09 points above baseline. On the contrary, non-exacerbators showed a negligible increase in BODE at two years (0.07 points), which differed significantly from that of the exacerbators ( $p<0.001$ ). Casanova, et al. used a different approach ${ }^{45}$. They compared the prognostic validity of longitudinally followed $\mathrm{FEV}_{1}$ and BODE in a study of over 700 patients over five years. The change in BODE index over time had less variability than the changes and variability of the $\mathrm{FEV}_{1}$. It also was a better predictor of mortality than any of the individual variables that integrate the BODE. In a different report from patients in the same cohort, Sanchez-Salcedo, et al. compared the progression of COPD in younger $(<55$ years) and older ( $>65$ years) patients ${ }^{46}$. BODE progressed similarly in both age groups, indicating that BODE can be used independent of age, as has been also observed in women ${ }^{47}$. All of these results support the concept that BODE can be used to define COPD progression and, more importantly, provide evidence that it can be used to stage the disease as it changes with time.

\section{BODE to monitor response to therapy}

The first evaluation of BODE as a surrogate marker of response to therapy was completed by Imfeld, et al. in a clinical study of 186 patients with severe emphysema ${ }^{48}$. They tested the predictive value of BODE following lung volume reduction surgery (LVRS) and found that the post-operative BODE, but not pre-operative BODE, predicted survival. The LVRS resulted in improvement in BODE from 7.2 (quartile 4), to 4.0 (quartile 2) $(\mathrm{p}<0.001)$. Those patients having the most improvement in BODE had the best five-year survival (HR: 0.497; 95\% CI: 0.375-0.659; $\mathrm{p}<0.001)$. The investigators found that the BODE index was able to predict the risk of death (ROC, AUC: 0.74), better than the FEV 1 (ROC, AUC: 0.63). Martinez, et al. in the NETT study randomized over 1000 patients with inhomogeneous emphysema to either LVRS or medical treatment ${ }^{32}$. The LVRS resulted in significant improvement in the BODE index compared with patients randomized to the medical arm. Importantly, a decrease of one unit of BODE at six months predicted survival at 1,2, and 5 years after randomizations, whereas an increase in one unit was associated with decreased survival.

Pulmonary rehabilitation (PR) is known to improve several of the surrogate markers for mortality in COPD, namely dyspnea, health status, and exercise capacity. Based on this observation, it was hypothesized that PR would modify the stage of COPD and the risk for mortality as measured by the BODE in$\mathrm{dex}^{49}$. In this study, of the 246 patients who 
qualified for and were offered rehabilitation, 116 accepted and completed the eight-week, three-times weekly rehabilitation program; 130 declined participation. The changes in BODE scores were compared between rehabilitated patients and non-PR participants. The patients had severe COPD both by FEV and by BODE. Patients were followed for more than two years or until death. Approximately $30 \%$ of the patients who graduated from PR joined a maintenance program and exercised three-times weekly for the entire two-year period. Following PR, 71\% of the participating patients improved their BODE index scores by at least one point; of these 25\% improved by two points. After graduation from PR, the BODE index decreased significantly from 5.07 to 4.18. This resulted in a "shift" from the third quartile to the second quartile, and their initially predicted mortality of $20-30 \%$ changed to an observed mortality of $11.2 \%$. Patients who declined PR had a worse BODE index at entry of 6.94 (approaching BODE fourth quartile), and in this group there was almost a $20 \%$ worsening of BODE index over time. This group of patients had the highest mortality rate $(50 \%)$. For patients who responded to PR, defined as an improvement in the BODE index score of at least one point, BODE index scores improved by a statistically significant $25 \%$ at three months, compared with the patients who did not respond to rehabilitation. These improvements in BODE index scores were maintained for a full two years after the start of PR, while patients who did not participate in PR displayed an $18 \%$ deterioration in BODE index scores. Bu, et al., in Australia, enrolled 56 patients with COPD in an observational study, following them for two years ${ }^{50}$. A total of 33 patients worsened their BODE, in 18 the BODE remained unchanged, and it improved in five. Patients whose BODE index increased had more exacerbations, hospitalizations, and longer hospital stay.

Taken together, the response of patients to exacerbations, LVRS, and PR can be captured by the BODE index, not only reflecting changes on disease severity, but also a marker of outcome, suggesting that the BODE index can be used as both surrogate marker for mortality, a staging tool, and also a tool to assess disease modification.

\section{CONCLUSIONS}

The severity of a disease is determined using variables that are associated with likelihood of death and, second and importantly, they should reflect organ compromise or failure resulting from disease progression. Simple to use, the validated multi-dimensional BODE index predicts survival, respiratory death, and organ failure better than its individual components. The BODE index captures the multiple pulmonary and systemic manifestations of COPD, and is proving to be a valuable tool not only in the assessment of severity and progression of disease, but also in evaluating the response to therapeutic interventions. More studies are needed to determine the value of BODE in clinical practice.

\section{REFERENCES}

1. Murray CJ, Lopez AD. Measuring the global burden of disease. N Engl Med. 2013;369:448-57.

2. Lopez AD, Mathers CD. Measuring the global burden of disease and epidemiological transitions: 2002-2030. Ann Trop Med Parasitol. 2006;100:481-99.

3. Celli BR, MacNee W. Standards for the diagnosis and treatment of patients with COPD: a summary of the ATS/ERS position paper. Eur Respir J. 2004;23:932-46.

4. Vestbo J, Hurd SS, Agusti AG, et al. Global strategy for the diagnosis, management and prevention of chronic obstructive pulmonary disease, GOLD executive summary. Am J Respir Crit Care Med. 2013;187:347-65. 
5. Fabbri LM, Rabe KF. From COPD to chronic systemic inflammatory syndrome? Lancet. 2007;370:797-9.

6. Kostikas K, Bakakos P, Papiris S, Stolz D, Celli BR. Systemic biomarkers in the evaluation and management of COPD patients: are we getting closer to clinical application? Curr Drug Targets. 2013;14:177-91.

7. Sin DD, Man SF. Systemic inflammation and mortality in chronic obstructive pulmonary disease. Can J Physiol Pharmacol. 2007;85:141-7.

8. Anthonisen NR, Wright EC, Hodgkin JE. Prognosis in chronic obstructive pulmonary disease. Am Rev Respir Dis. 1986;133:14-20.

9. Almagro P, Martinez-Camblor P, Soriano JB, et al. Finding the best thresholds of FEV1 and dyspnea to predict 5-year survival in COPD patients: the COCOMICS study. PLoS One. 2014;9:e89866.

10. Kanner RE, Renzetti AD, Stanish WM, Barkman HW, Klauber MR. Predictors of survival in subjects with chronic airflow limitation. Am J Med. 1983;74:249-55.

11. Vestbo J, Edwards LD, Scanlon PD, et al. Changes in forced expiratory volume in 1 second over time in COPD. N Engl J Med. 2011;365:1184-92.

12. Nishimura K, Izumi T, Tsukino M, Oga T. Dyspnea is a better predictor of 5 -year survival than airway obstruction in patients with COPD. Chest. 2002;121:1434-40.

13. Pierson DJ. Pathophysiology and clinical effects of chronic hypoxia. Respir Care. 2000;45:39-51

14. Casanova C, Cote C, de Torres JP, et al. Inspiratory-to-total lung capacity ratio predicts mortality in patients with chronic obstructive pulmonary disease. Am J Respir Crit Care Med. 2005;171:591-7.

15. O'Donnell DE, Laveneziana P. The clinical importance of dynamic lung hyperinflation in COPD. COPD. 2006;3:219-32.

16. Barbera JA, Blanco I. Pulmonary hypertension in patients with chronic obstructive pulmonary disease: advances in pathophysiology and management. Drugs. 2009;69:1153-71.

17. Schols AM, Broekhuizen R, Weling-Scheepers CA, Wouters EF. Body composition and mortality in chronic obstructive pulmonary disease. Am J Clin Nutr. 2005;82:53-9.

18. Pinto-Plata VM, Cote C, Cabral H, Taylor J, Celli BR. The 6-min walk distance: change over time and value as a predictor of survival in severe COPD. Eur Respir J. 2004;23:28-33.

19. Cote CG, Casanova C, Marin JM, et al. Validation and comparison of reference equations for the 6-min walk distance test. Eur Respir J. 2008;31:571-8.

20. Oga T, Nishimura K, Tsukino M, Sato S, Hajiro T. Analysis of the factors related to mortality in chronic obstructive pulmonary disease: role of exercise capacity and health status. Am J Respir Crit Care Med. 2003;167:544-9.

21. Cote C, Zilberberg MD, Mody SH, Dordelly LJ, Celli B. Haemoglobin level and its clinical impact in a cohort of patients with COPD. Eur Respir J. 2007;29:923-9.

22. Krishnan G, Grant BJ, Muti PC, et al. Association between anemia and quality of life in a population sample of individuals with chronic obstructive pulmonary disease. BMC Pulm Med. 2006;6:23.

23. Divo M, Cote C, de Torres JP, et al. Comorbidities and risk of mortality in patients with chronic obstructive pulmonary disease. Am J Respir Crit Care Med. 2012;186:155-61.

24. Vanfleteren LE, Spruit MA, Groenen M, et al. Clusters of comorbidities based on validated objective measurements and systemic inflammation in patients with chronic obstructive pulmonary disease. Am J Respir Crit Care Med. 2013;187:728-35

25. Celli BR, Cote CG, Marin JM, et al. The body-mass index, airflow obstruction, dyspnea, and exercise capacity index in chronic obstructive pulmonary disease. N Engl J Med. 2004;350:1005-12.

26. Puhan MA, Garcia-Aymerich J, Frey M, et al. Expansion of the prognostic assessment of patients with chronic obstructive pulmonary disease: the updated BODE index and the ADO index. Lancet. 2009;374:704-11.

27. Ong KC, Earnest A, Lu SJ. A multidimensional grading system (BODE index) as predictor of hospitalization for COPD. Chest. 2005;128:3810-16.

28. Marin JM, Carrizo SJ, Casanova C, et al. Prediction of risk of COPD exacerbations by the BODE index. Respir Med. 2009;103:373-8.
29. Soler-Cataluna JJ, Martinez-Garcia MA, Sanchez LS, Tordera MP, Sanchez PR. Severe exacerbations and BODE index: two independent risk factors for death in male COPD patients. Respir Med. 2009;103:692-9.

30. Cardoso F, Tufanin AT, Colucci M, Nascimento O, Jardim JR. Replacement of the 6-min walk test with maximal oxygen consumption in the BODE Index applied to patients with COPD: an equivalency study. Chest. 2007;132:477-82.

31. Williams JE, Green RH, Warrington V, Steiner MC, Morgan MD, Singh SJ. Development of the i-BODE: validation of the incremental shuttle walking test within the BODE index. Respir Med. 2012;106:390-6.

32. Martinez FJ, Han MK, Andrei AC, et al. Longitudinal change in the BODE index predicts mortality in severe emphysema. Am J Respir Crit Care Med. 2008;178:491-9.

33. Jones RC, Donaldson GC, Chavannes NH, et al. Derivation and validation of a composite index of severity in chronic obstructive pulmonary disease: the DOSE Index. Am J Respir Crit Care Med. 2009;180:1189-95.

34. Kostianev SS, Hodgev VA, Iluchev DH. Multidimensional system for assessment of COPD patients. Comparison with BODE index. Folia Med (Plovdiv). 2008;50:29-38.

35. Esteban C, Quintana JM, Moraza J, et al. BODE-Index vs HADO-score in chronic obstructive pulmonary disease: Which one to use in general practice? BMC Med. 2010;8:28.

36. Briggs A, Spencer M, Wang H, Mannino D, Sin DD. Development and validation of a prognostic index for health outcomes in chronic obstructive pulmonary disease. Arch Intern Med. 2008;168:71-9.

37. Omachi TA, Yelin EH, Katz PP, Blanc PD, Eisner MD. The COPD severity score: a dynamic prediction tool for health-care utilization. COPD. 2008;5:339-46

38. Mehrotra N, Freire AX, Bauer DC, et al. Predictors of mortality in elderly subjects with obstructive airway disease: the PILE score. Ann Epidemiol. 2010;20:223-32

39. Schembri S, Anderson W, Morant S, et al. A predictive model of hospitalisation and death from chronic obstructive pulmonary disease. Respir Med. 2009;103:1461-7.

40. Almagro P, Soriano JB, Cabrera FJ, et al. Short-and medium-term prognosis in patients hospitalized for COPD exacerbation: the CODEX index. Chest. 2014;145:972-80.

41. Marin JM, Alfageme I, Almagro P, et al. Multicomponent indices to predic survival in COPD: The COllaborative COhorts to assess multicomponen indices of COPD in Spain-COCOMICS study. Eur Respir J. 2013;42:323-32.

42. de Torres JP, Casanova C, Marin JM, et al. Prognostic evaluation of COPD patients: GOLD 2011 versus BODE and the COPD comorbidity index COTE. Thorax. 2014;69:799-804.

43. Moons KG, Royston P, Vergouwe Y, Grobbee DE, Altman DG. Prognosis and prognostic research: what, why, and how? BMJ. 2009;338:b375.

44. Cote CG, Dordelly LJ, Celli BR. Impact of COPD exacerbations on patient-centered outcomes. Chest. 2007;131:696-704

45. Casanova C, Aguirre-Jaíme A, de Torres J, et al. Longitudinal assessment in COPD patients: multidimensional variability and outcomes. Eur Respir J. 2014;43:745-53

46. Sanchez-Salcedo P, Divo M, Casanova C, et al. Disease progression in young patients with COPD: rethinking the Fletcher and Peto model. Eur Respir J. 2014;44:324-31.

47. de Torres JP, Casanova C, de Garcini AM, Jaime AA, Celli BR. COPD het erogeneity: gender differences in the multidimensional BODE index. Int Chron Obstruct Pulmon Dis. 2007;2:151-5.

48. Imfeld S, Bloch KE, Weder W, Russi EW. The BODE index after lung volum reduction surgery correlates with survival. Chest. 2006;129:873-8.

49. Cote CG, Celli BR. Pulmonary rehabilitation and the BODE index in COPD. Eur Respir J. 2005;26:630-6.

50. Bu XN, Yang T, Thompson MA, Hutchinson AF, Irving LB. Changes in the BODE index, exacerbation duration and hospitalisation in a cohort of COPD patients. Singapore Med J. 2011;52:894-900.

51. Esteban C, Quintana JM, Aburto M, Moraza J, Capelastegui A. A simple score for assessing stable chronic obstructive pulmonary disease. QJM. 2006;99:751-9. 